\title{
Valorization of Cyprinus Carpio skin for biocompatible collagen hydrolysates with potential application in foods, cosmetics and pharmaceuticals
}

\section{Elena Danila}

Politehnica University of Bucharest, Faculty of Applied Chemistry and Materials

Raluca Stan ( $\square$ rl_stan2000@yahoo.com )

Politehnica University of Bucharest: Universitatea Politehnica din Bucuresti https://orcid.org/00000002-4490-5173

\section{Mădălina ALBU KAYA}

Leather and Footwear Research Institute

\section{Georgeta VOICU}

Politehnica University of Bucharest: Universitatea Politehnica din Bucuresti

\section{Maria Minodora MARIN}

Politehnica University of Bucharest: Universitatea Politehnica din Bucuresti

\section{Alina MOROSAN}

Politehnica University of Bucharest: Universitatea Politehnica din Bucuresti

Irina TITORENCU

ICBP: Institutul de Biologie si Patologie Celulara Nicolae Simionescu

\section{Raluca TUTUUIANU}

ICBP: Institutul de Biologie si Patologie Celulara Nicolae Simionescu

\section{Research Article}

Keywords: fish collagen hydrolysates, Cyprinus carpio skin, neutral hydrolysis, biocompatibility

Posted Date: February 16th, 2021

DOI: https://doi.org/10.21203/rs.3.rs-227096/v1

License: (c) (i) This work is licensed under a Creative Commons Attribution 4.0 International License. Read Full License 


\section{Abstract}

Fish collagen is the safest source of collagen at present, the extraction being performed on secondary sources as skin, bones, scales or fins resulted after fish processing. The aim of the present study was to obtain biocompatible collagen hydrolysates from waste Cyprinus carpio skin, the main aquaculture species in Romania using an inexpensive and "green" neutral hydrolysis process.

Neutral hydrolysis of pretreated fish skins performed for 6 hours at a temperature of $135^{\circ} \mathrm{C}$ and a pressure of $315 \mathrm{kPa}$ produced collagen hydrolysates in 24.6-35.5\% yields depending on the adopted pretreatment procedure. The extensive characterization of hydrolysate samples revealed a high purity degree $(98 \%$ protein content, undetected ash content, $\mathrm{pH}$ value in the range 6-7), also confirmed by the absence of undesired aggregates in the characteristic fibril structure as determined by electronic microscopy. A specific collagen hydrolysate random coil structure and the absence of triple helix was determined by FTIR analysis and sustained by CD spectroscopy and X-ray diffraction. The biocompatibility assessment for the obtained fish collagen hydrolysates revealed no cytotoxic effect on Human keratinocytes, with an $80 \%$ cell viability, superior as compared to conventional bovine collagen hydrolysate.

Neutral hydrolysis of waste Cyprinus carpio skin yielded collagen hydrolysates with determined characteristics and biocompatibility superior to bovine collagen, suitable for application in foods, cosmetics and pharmaceutical industry.

\section{Novelty Statement}

An inexpensive procedure, neutral hydrolysis in mild conditions, was applied on waste Cyprinus carpio skin, the major type of fish consumed in Romania with $8000 \mathrm{t} /$ production, to obtain collagen hydrolysates. The targeted starting material, waste carp skin represents $6-9 \%$ of the total fish mass, and according to literature data may provide collagen hydrolysates with a lower molecular mass and increased bioavailability being up to 1.5 times more efficiently absorbed by the body than bovine or porcine collagen. Prior to neutral hydrolysis, several pretreatment procedures involving affording materials were investigated, and biocompatibility of resulted samples with a high purity degree was assessed as compared to commercial bovine collagen hydrolysate proving a superior cell viability on human keratinocytes.

\section{Introduction}

Collagen is the most abundant fibrillar protein (approximately 30\%) in the body of vertebrates, found in various organs and tissues: tendons, skin, bones, cartilage, blood vessel walls, muscles, heart, liver, kidneys, central nervous system, basement membrane, etc. In the human body, collagen represents one third of the total protein, based on the dry weight of the skin and is the most important component of the extracellular matrix (ECM) [1]. Collagen is a natural polymer consisting of 20 amino acids, arranged in characteristic sequences for the collagen molecule, which has a unique conformational structure of triple helix. In the collagen composition the amino acids with the highest percentage are: Glycine (Gly) - 33\%, 
Proline (Pro) $-12-13 \%$, Alanine (Ala) - 11\% and Hydroxyproline (Hyp) $-9-10 \%$, the latter being the amino acid considered as characteristic [2, 3].

Collagen is part of a family of so-called "isotypes", genetically different. The term isotype refers to the fact that there are several types of macromolecular substances that structurally have both common and different elements, in order to be individualized. Until the present, there are known 29 types of collagen that are encoded by at least 44 genes. The types of collagen were grouped into 8 classes, depending on the structural similarities and the quaternary, polymeric exchanges that they form [4]. The most important natural sources of collagen are the skin, tendons, cartilage and bones, nowadays collagen extraction being performed predominantly on starting materials of bovine and porcine nature. Alternative extraction sources have been explored over the past 10-15 years such as fish collagen, thus reducing the risk of the transference of zoonotic diseases such as BSE (bovine spongiform encephalopathy), TSE (transmissible spongiform encephalopathy), and FMD (Foot and Mouth Disease) or even avoiding religious constraints [5].

Fish collagen is considered as one of the safest sources of collagen, the extraction being performed using secondary raw materials such as skin, bones, scales or fins resulted after fish processing. One reason for approving the safety of this source is the belief that life "comes from the marine environment". However, the extraction of fish collagen is more complex, requires extensive time schedule with a low extraction efficiency and higher costs than for other sources of collagen extraction. Type I collagen is obtained from the skin and bones, type II collagen from cartilage, and type IV collagen can be extracted from the sea sponges [6]. Besides the low risk of allergies, fish collagen is up to 1.5 times more efficiently absorbed by the body than bovine or porcine collagen, proving a higher bioavailability, due to the lower molecular mass of its component polypeptides compared to other types of collagen [7].

Nowadays, fish collagen has a wide range of applications in the health-related sectors, namely in cosmetics, the pharmaceutical industry and in medical care (including plastic surgery, orthopedics, ophthalmology, dentistry etc.) [8] and in the food sector (food processing, as additive and nutraceuticals) [9].

Fish skin collagen hydrolysates are mainly obtained by acid and enzymatic hydrolysis, extensive studies upon the nature of the obtained peptides and method optimization being reported in the literature [9]. Enzymatic hydrolysis leads to superior extraction yields than acid procedure but requires a subsequent purification by ultrafiltration, gel filtration, desalination, etc. [10,11].

As an alternative, neutral hydrolysis of proteins, referred as subcritical water hydrolysis (SWH) using water at a temperature of $100-374^{\circ} \mathrm{C}$ and a pressure of $0.1-22 \mathrm{MPa}$ is a greener processing technique that does not introduce chemicals or produce salt and toxic waste and it requires a short reaction time. The mechanism that underlies SWH is the formation of hydronium $\left(\mathrm{H}_{3} \mathrm{O}+\right)$ and hydroxide $\left(\mathrm{OH}^{-}\right)$ions that act as catalysts due to the subcritical condition of water. The method was successfully applied on different protein containing food wastes and parameters (temperature, pressure) were optimized to control the conversion of protein into peptides or free aminoacids [12]. Tuna skin collagen hydrolysates with 
antioxidant and antimicrobial potential have been successfully obtained by SWH working at temperatures of $150-300^{\circ} \mathrm{C}$ and pressure of 5-10 MPa [13].

The aim of the present study was to obtain biocompatible collagen hydrolysates from Cyprinus carpio skin, the main aquaculture species in Romania, with a 8000t/year production, using a neutral inexpensive hydrolysis process involving lower temperature $\left(135^{\circ} \mathrm{C}\right)$ and pressure values $(315 \mathrm{kPa})$ employing various pretreatment procedures. The targeted starting material, waste carp skin represents $6-9 \%$ of the total fish mass, representing an important source of fish collagen hydrolysates. The performance of the employed procedures was estimated by an extensive characterization of the obtained samples (physico-chemical analyses, infrared spectroscopy, optical and scanning electron microscopy, circular dichroism spectroscopy, X-ray diffraction, isoelectric point, biocompatibility), in order to provide helpful information for the potential application of carp skin collagen hydrolysates in cosmetics, food and pharmaceutical industry.

\section{Materials And Methods}

\subsection{Chemicals}

All the reagents and solvents of analytical grade were purchased from Sigma-Aldrich and used with no further purification. Distilled water was used in all the experiments.

\subsection{Fish collagenhydrolysates extraction}

Romanian carp (Cyprinus carpio) skin was purchased from a local market and kept at $-25^{\circ} \mathrm{C}$ until processing. First the fish skin was thawed, cut into smaller pieces and washed with a $2 \%$ organic detergent solution for 2-3 hrs. Throughout the extraction process the fish skin was kept at a temperature below $10^{\circ} \mathrm{C}$, because the denaturation temperature of the fish collagen is lower than the bovine one [14]. Further skin fish was subjected to the following pretreatment procedures:

a) Acid treatment. The fish skin was divided into three samples and subjected to acid treatment by soaking in acid solution for 24 hours at at $4^{\circ} \mathrm{C}$, skin: acid solution ratio $1: 3(\mathrm{~m} / \mathrm{v})$, for removal of the meat, scales and some of the fat attached to the skin. Sample 1 was treated with a $3 \%$ lactic acid solution, sample $\mathbf{2}$ was treated with $3 \%$ citric acid, and sample $\mathbf{3}$ was treated with $3 \%$ citric and lactic acid mixture in $1: 1$ ratio, respectively.

b) Alkaline treatment. The fish skin samples 1-3 were firstly washed with cold water for 2-3 hours until the wash water had faintly acid or neutral $\mathrm{pH}$ and then subjected to an alkaline treatment, by soaking for 24 hours at $4^{\circ} \mathrm{C}$ to remove non-collagenous proteins. The lactic acid treated sample 1 was subsequently divided into 3 samples treated as follows: $\mathrm{NaCl} 1 \mathrm{M}$, at a skin:saline solution ratio 1:5 (m/v) resulting HO4P2, $1 \mathrm{M} \mathrm{NaHCO}_{3}$, skin: alkaline solution ratio 1:10 (m/v) resulting HO4P3, and treatment with $1 \mathrm{M}$ $\mathrm{NaOH}$, skin: alkaline solution ratio 1:10 (m/v) resulting H04P5, respectively. The fish skin sample 2 was 
treated with $1 \mathrm{M} \mathrm{NaOH}$, skin: alkaline solution ratio 1:10 (m/v) resulting H04P4, the same treatment being performed on fish skin sample 3 resulting H04P1.

c) Ethanol 15\% treatment. The H04P1-H04P5 samples were cold water-washed for 6 hours, changing the water every hour, until the wash water had faintly alkaline or neutral $\mathrm{pH}$ and then were subjected to a treatment with $15 \%$ ethanol in order to remove fats, by soaking for 24 hrs at a skin: $15 \%$ ethanol ratio $1: 10$ (w: v).

d) Hydrogen peroxide 1\%treatment: The skin samples were cold water washed for 6 hours, changing the water every hour, and then were subjected to a treatment with $1 \%$ hydrogen peroxide, by soaking for 24 hrs at a skin: $1 \%$ hydrogen peroxide ratio $2: 5(w: v)$, in order to remove pigments.

e) Neutral hydrolysis: After washing with cold water by soaking for 12 hours, the samples were subjected to a neutral hydrolysis process using an autoclave 3850 ELV CGP (Tuttnauer). A mixture of pretreated fish skin and distilled water in 1:3 ratio was placed in a metal recipient and heated for 6 hours at a temperature of $135^{\circ} \mathrm{C}$ and a pressure of $315 \mathrm{kPa}$. Liquid hydrolysates were separated by filtration.

f) Freeze-drying: Liquid hydrolysates were freeze-dried using a DELTA 2-24 LSC freeze dryer (Christ, Germany) obtaining yellowish-white powders, slightly pearlescent of fish collagen hydrolysate.

The yield of collagen was calculated and expressed as percentage by Eq. (1) [15]:

\section{Yield of collagen $=\frac{\text { Weight of collagen,g }}{\text { Weight of dry skin,g }} \times 100$}

\subsection{Physico-chemical characterization}

Multiple physico-chemical analyses using standardized methods were performed for the characterization of the carp skin collagen hydrolysates as follows: gravimetric methods for dry substance content (SR EN ISO 4684:2006) and total ash content (SR EN ISO 4047:2002) by drying at constant mass at $102 \pm 2^{\circ} \mathrm{C}$ and by calcining at $800^{\circ} \mathrm{C}$, respectively; volumetric methods for total nitrogen content (Kjeldahl method) and protein substance (SR ISO 5397:1996), aminic nitrogen according to a Leather and Footwear Research Institute (ICPI) internal protocol; potentiometric method for $p H$ value (SR EN ISO 4045:2008).

\subsection{Infrared spectroscopy (FT-IR)}

The determinations were made using an FTIR spectrometer (Jasco, model 4200, Jasco Europe S.R.L., Milan, Italy) by the method of total reflection attenuated (FT-IR ATR) under the following conditions: wavelength range, $4000-600 \mathrm{~cm}^{-1}$; resolution, $4 \mathrm{~cm}^{-1}$; radiation angle of incidence, $45^{\circ}$; the IR radiation is directed through the germanium crystal towards the diamond sensor, on the surface of which is placed the sample to be analyzed. For deconvolution experiments, FTIR spectroscopic analysis was performed on a Nicolet is 50 FT-IR spectrometer using an integral diamond ATR unit; the measurements were carried 
out in the range of $4000-400 \mathrm{~cm}^{-1}$, using the resolution $8 \mathrm{~cm}^{-1}$ and co-adding 64 scans per each spectrum. Fourier self-deconvolution was conducted on the average spectra for the amide I band using Fityk 1.3.1 (Function type: Voight).

\subsection{Circular Dichroism Spectroscopy (CD)}

The secondary structure of collagen extracts from fish was evaluated by CD. Spectra acquisition was performed on a Jasco J-1500 Circular Dichroism Spectrophotometer model, Japan using a quartz cell with $\mathrm{I}=1 \mathrm{~mm}$. For each determination, $500 \mu \mathrm{L}$ of aqueous collagen hydrolyzed solution of $0.025 \%$ concentration was used. CD spectra were obtained by triplicate scanning, using the spectral range 170 $260 \mathrm{~nm}$, with a scan speed of $100 \mathrm{~nm} / \mathrm{min}$.

\subsection{X-ray diffraction (XRD) analysis}

The composition and crystallinity degree of these materials were assessed by X-ray diffraction, which was performed using a Shimadzu XRD 6000 diffractometer, with Ni-filtered CuK a radiation ( $a=1.5406 \AA$ ) , 2 theta in $5-30^{\circ}$ range by a step of $0.02^{\circ}$ and an angular speed of $2 \% \mathrm{~min}$.

\subsection{Determination of isoelectic point (pl)}

The isoelectric point was measured by determining the electrophoretic mobility of the systems at different $\mathrm{pH}$ values, using the ZetaSizer Nano, Malvern, Zeta Protein module. A sample of $3 \mathrm{mg}$ of collagen was solubilized in $3 \mathrm{~mL}$ PBS (Phosphate-buffered saline) with different $\mathrm{pH}$ values (2-8), then $1 \mathrm{~mL}$ of $5 \mathrm{mM}$ $\mathrm{NaCl}$ solution (electrolyte role) was added. Collagen hydrolysates samples solubilized with electrolyte content were placed in special cells and subjected to analysis in 3 cycles of 30 measurements.

2.8. Optical microscopy analysis was performed using a LEICA optical microscope model S8AP0, with Increase Power: 20-160x. The images were captured by an attached Nikon Coolpix MCD camera (Japan). The results are presented in supporting information section figure S2.

\subsection{Scanning electron microscopy (SEM)}

The morphology of the collagen hydrolysates samples was investigated by scanning electron microscopy (SEM), using a HITACHI S2600N equipment coupled with EDX spindle. Powder samples for SEM analyses were covered with a thin silver layer deposited by dc-sputtering.

\subsection{Biocompatibility assessment}

Human adult keratinocytes (HaCaT cell line) were cultured in DMEM $4.5 \mathrm{~g} / \mathrm{L}$ glucose, with 10\% fetal bovine serum (FBS), at $37^{\circ} \mathrm{C}$ and $5 \% \mathrm{CO}_{2}$. Cells were seeded at $10000 \mathrm{cells} / \mathrm{cm}^{2}$, and after $24 \mathrm{~h}$, the medium was changed with complete medium supplemented with 1\% collagen hydrolysates. After 6 days, with one medium changed at day 3 , the cellular morphology was investigated using phase contrast microscopy (Zeiss Axio Vert.A1, Germany) and the cell viability was quantified using the XTT (2,3-Bis- (2methoxy-4-nitro5-sulfophenyl) -2H-tetrazolium-5-carboxanilide) method according to the manufacturer's 
specifications (Thermo Scientific). The experiments were performed in triplicate and the results reported as percentage of control (cells grown in complete medium) and expressed as mean \pm standard deviation [31].

\section{Statistical Analyses}

All physico-chemical experiments were performed in triplicate $(n=3)$. The data are expressed as mean \pm Standard Deviation SD. Statistical analysis was performed using GraphPad Prism software also for biocompatibility assessment. The significance of differences was evaluated by single factor ANOVA test and it was considered significant if $\mathrm{P}<0.05$.

\section{Results And Discussion}

\subsection{Fish collagen hydrolysate extraction}

Most reported methods for extraction of collagen hydrolysate from fish skin use enzymatic or acid hydrolysis through several stages, with the disadvantage that in the skin processing step, residues such as scales, bones, meat or fat are manually removed, a process that can take a long time and may be inefficient for the total removal of these residues. Other disadvantages reside in the cost of enzymes, the long hydrolysis time and the difficulty of purification of the final product, residues of acids or enzymes affecting the properties of the final product.

The method proposed in the present paper eliminates some of these disadvantages by using neutral hydrolysis, employing water in subcritical conditions at $135^{\circ} \mathrm{C}$ and $315 \mathrm{kPa}$. Several pretreatment procedures were developed for removing residues (scales, bones, meat or fat), non-colagenous proteins and pigments involving food and cosmetic compatible organic acids (lactic and citric acid), mild alkaline or saline treatment, diluted ethanol and hydrogen peroxide, respectively, as presented in Fig. 1. The solvent concentrations involved in the extraction process were chosen based both on our previous experience in obtaining collagen and on other studies reported in the literature ${ }^{5}$.

After the hydrolysis process, the samples were stored at $4^{\circ} \mathrm{C}$ for 24 hours. In most of the cases, stable solid hydrolysates were obtained except for the sample H04P5, resulted after employing lactic acid and $\mathrm{NaOH}$ in the separation process which yielded gelatin, proving this treatment unsuitable for obtaining fish skin hydrolysate.

Collagen hydrolysates extraction yields for different process conditions were obtained as follows: $35.5 \%$ for H04P1 (3\% lactic and citric acids, $\mathrm{NaOH} 1 \mathrm{M}$ ), $28.1 \%$ for HO4P2 (3\% lactic acid, $\mathrm{NaCl} 1 \mathrm{M}$ ), $24.6 \%$ for H04P3 ( $3 \%$ lactic acid, $\mathrm{NaHCO}_{3} 1 \mathrm{M}$ ), and $29.3 \%$ for $\mathrm{HO} 4 \mathrm{P} 4$ (3\% citric acid, $\mathrm{NaOH} 1 \mathrm{M}$ ), respectively. The mixture of organic acids and $\mathrm{NaOH} 1 \mathrm{M}$ pre-hydrolysis treatment (sample H04P1) proved to be the most efficient procedure. The obtained extraction yields are in good agreement with acid soluble collagen obtained from carp skin, Cyprinus carpio- 41.3\% [16] and Ctenopharyngodon idellus -25.5\% [17]. Literature data report different extraction yields for acid soluble fish skin collagen (red Snapper $-5.71 \%$, milkfish 
$-4.00 \%$, paper nautilus $-55.2 \%$, Japanese sea-bass $-51.4 \%$, chub mackerel $-49.8 \%$, bullhead shark $-50.1 \%$ ) explained as a difference in solubility in acid solutions due to the degree of cross-linking of collagen molecules [16].

\subsection{Physico-chemical characterization}

Physicochemical parameters and the estimations of collagen content are important data in evaluating the potential value of fish collagen hydrolysates. Thus, the obtained Cyprinus carpio skin collagen hydrolysates H04P1-H04P4 were subjected to a standard physico-chemical characterization, the results are presented in Table 1:

Examining the data from Table 1 we may conclude that all the obtained fish collagen hydrolysates samples present a high degree of purity according to the very high percentage of protein (about $98 \%$ ) and undetected values for ash content, which represent two important advantages of the extraction method employed. By comparison, reported literature data for acid soluble Cyprinus carpio skin collagen hydrolysate show a percentage of protein of $27-27.9 \%$ and an ash content of $0.22-1.21 \%$ [18]. The proposed procedure for the separation of collagen hydrolysates yielded samples with $\mathrm{pH}$ values in the range 6-7, which indicates the suitability of obtained carp skin hydrolysates for food supplements or cosmetics.

Additional information resulted by examining the values for total nitrogen, $\mathrm{N}_{\mathrm{t}}$ and amino nitrogen $\left(\mathrm{NH}_{2}\right)$ in order to obtain an estimation of the degree of hydrolysis, $\mathrm{DH}$, according to literature data (eq 2) [19]:

$$
D H(\%)=\frac{\text { Amino nitrogen }(\mathrm{NH} 2)}{\text { Total Nitrogen }(\mathrm{Nt})} \times 100(2)
$$

As the degree of hydrolysis increases, the average molecular mass of the hydrolysate decreases, the latter being also correlated with the amine nitrogen content $[20,21]$. Thus, H04P2 is the hydrolysate with the highest molecular weight ( $\mathrm{DH}$ value $3.16 \%$, estimated average molecular mass $>25000 \mathrm{Da}$ ) whilst H04P4 is the hydrolysate with the lowest molecular weight ( $\mathrm{DH}$ value $26.49 \%$, estimated average molecular mass $<3000 \mathrm{Da}$ ). This may be explained by the differences in the applied treatment, pKa value of the acid involved in the pretreatment step and the nature of non-collagenous protein removal agent: sample H04P2 was obtained after treatment with lactic acid ( $\mathrm{pKa}=3.85$ ) and by using $\mathrm{NaCl} 1 \mathrm{M}$ for removing noncollagenous proteins whilst HO4P4 resulted after pretreatment with citric acid $\left(\mathrm{pKa}_{1}=3.13\right)$ and with $\mathrm{NaOH} 1 \mathrm{M}$, respectively which may cause a partial hydrolysis and by consequence a lower molecular weight of the fragments.

\subsection{Infrared spectroscopy (FT-IR)}

The structure of collagen hydrolysates samples was confirmed by FT-IR spectroscopy as revealed by comparative IR spectrum for collagen hydrolysates in Fig. 2, similar with other fish collagen hydrolysates 
reported in the literature. The identified absorption bands are characteristic of the functional groups specific to collagen [22]:

- amide A, due to vibrations of the secondary amine group (-NH-), peaks from: $3282 \mathrm{~cm}^{-1}$ (HO4P1), 3285 cm-1 (HO4P2), $3286 \mathrm{~cm}^{-1}$ (HO4P3), $3289 \mathrm{~cm}^{-1}$ (HO4P4);

- amide B, due to the vibrations of the methylene group $\left(-\mathrm{CH}_{2}-\right)$, peaks from: $3076 \mathrm{~cm}^{-1}$ (HO4P1), $3077 \mathrm{~cm}^{-1}$ (H04P2), $3077 \mathrm{~cm}^{-1}$ (HO4P3), $3077 \mathrm{~cm}^{-1}$ (HO4P4);

- aliphatic groups $-\mathrm{CH}_{2}$ and $-\mathrm{CH}_{3}$, attributed to stretching vibrations, peaks from $2929 \mathrm{~cm}^{-1}$ (HO4P1), 2931 $\mathrm{cm}^{-1}$ (HO4P2), $2923 \mathrm{~cm}^{-1}$ (HO4P3), $2927 \mathrm{~cm}^{-1}$ (HO4P4);

- aliphatic groups $-\mathrm{CH}_{2}$ and $-\mathrm{CH}_{3}$, attributed to valence, symmetrical and asymmetric vibrations, located at: $1440 \mathrm{~cm}^{-1}$ (HO4P1), $1442 \mathrm{~cm}^{-1}$ (HO4P2), $1442 \mathrm{~cm}^{-1}$ (HO4P3), $1442 \mathrm{~cm}^{-1}$ (H04P4);

- amide I, due to the stretch vibrations of the carbonyl group (= CO), peaks from: $1629 \mathrm{~cm}^{-1}$ (HO4P1), 1631 cm-1 (HO4P2), $1631 \mathrm{~cm}^{-1}$ (HO4P3), $1635 \mathrm{~cm}^{-1}$ (HO4P4);

- amide II, due to the deformation vibrations of the secondary amine group (-NH) and the valence vibrations of the nitrile group (-CN), the peaks from: $1532 \mathrm{~cm}^{-1}$ (HO4P1), $1534 \mathrm{~cm}^{-1}$ (HO4P2), $1534 \mathrm{~cm}^{-1}$ (HO4P3), $1538 \mathrm{~cm}^{-1}$ (H04P4);

- amide III due to the same vibrations as in the case of amide II, peaks from: $1235 \mathrm{~cm}^{-1}$ (HO4P1), $1238 \mathrm{~cm}^{-}$ 1 (H04P2), $1238 \mathrm{~cm}^{-1}$ (HO4P3), $1238 \mathrm{~cm}^{-1}$ (HO4P4).

Deconvolution of amide band I (Figure S1, supplementary information) and quantitative band fitting analysis for the main component peaks (Table 2) provided interesting information on protein conformational changes in the obtained fish skin hydrolysates. According to literature data $[23,24]$ the component peaks obtained after deconvolution of amide band I for the examined collagen hydrolysate samples may be attributed as follows:

- Peak 1, 1625- $1628 \mathrm{~cm}^{-1}$ - intramolecular beta- sheets

- Peak 2, 1651-1656 $\mathrm{cm}^{-1}$ - random coil conformations, imide residues and a-like helix conformations

- Peak 3, 1665-1681 $\mathrm{cm}^{-1}$ - $\beta$-turns of the $\mathrm{C}$ - and $\mathrm{N}$-telopeptides in collagen

- Peak 4, 1691- $1694 \mathrm{~cm}^{-1}$ - gelatin and helices of aggregated collagen-like peptides

An intense absorption at $1660 \mathrm{~cm}^{-1}$ is generally attributed to the triple helix state of collagen ${ }^{22}$, a decrease of band intensity accompanied by enhancement of bands around $1630 \mathrm{~cm}^{-1}$ being generally associated with heat denaturation of collagen. Examining the deconvolution component peaks of amide I for the fish collagen hydrolysates samples, no triple helix characteristic absorption is observed, the most intense 
component being the one due to random coil conformations, imide residues and a-like helix conformations (Peak 2 at 1651-1656 $\mathrm{cm}^{-1}$ ). This conclusion was also sustained by the circular dicroism and XRD experiments, no triple helix structure being evidenced for all the obtained fish collagen hydrolysates.

\subsection{Circular Dichroism Spectroscopy (CD)}

Mechanical properties of collagen are greatly influenced by the existing triple helical structure and maintaining the integrity of this structure influence the further applications of the fish collagen hydrolysates. Information about the existence of triple helix structure were obtained by Circular Dichroism Spectroscopy, a spectroscopic method based on the differential absorption of left-right polarized circular light of chiral macromolecules, typically used to evaluate the secondary structure of proteins [25]. CD spectra of the analyzed fish collagen samples are presented in Fig. 3a.

All analyzed fish collagen hydrolysate samples showed a pronounced negative band around 196 to 200 $\mathrm{nm}$, typical of a random coil structure and no positive maximum at the wavelength $220 \mathrm{~nm}$, characteristic for the triple helix was observed. Thus, a specific structure characteristic for the denatured collagen (hydrolyzed collagen) was attributed to all fish collagen extracts H04P1- H04P4 [26]. Prevalence of random coil structure and no triple helix characteristic band are in good agreement with FT-IR spectra and intensity of component bands measured after deconvolution of amide I band, the highest intensity being observed for band 2, characteristic for random coil conformations. (Fig. S1).

\subsection{X-ray diffraction (XRD) analysis}

X-ray diffraction is often used to assess collagen fibril distribution and orientation in fish mineralized tissues. There are two peaks characteristic of collagen molecule and considered as a signature. The first one $\left(\sim 7^{\circ}\right)$ and sharpest is related to the triple helix conformation and distance between molecular chains, and the second peak $\left(\sim 20^{\circ}\right)$ is related to the distance between the skeletons. The X-ray spectra of lyophilized fish collagen hydrolysates samples presented in Fig. 3b reveal no sharp peak associated with the triple helical structure, due to the loosing of the native conformations of collagen during the hydrolysis process as confirmed also by FT-IR characteristic amide I band analysis and CD spectra. The second peak is present at $21.19^{\circ}$ (HO4P1), $19.18^{\circ}$ (HO4P2), $19.28^{\circ}$ (HO4P3) and $19.84^{\circ}$ (HO4P4), respectively. The Bragg equation $d(\AA)=\lambda / 2 \sin \theta$ (where $\lambda$ is the $X$-ray wavelength $(1.54 \AA$ ), and $\theta$ is the Bragg diffraction angle), was used to calculate the minimum value of the repeated spacings. The distance between skeletons were $4.18 \AA$ (H04P1), $4.62 \AA$ (H04P2), $4.59 \AA$ (HO4P3) and $4.47 \AA$ (H04P4) respectively, in good agreement with the reported values for collagen extracted from other fish species [27].

\subsection{Determination of isoelectric point (pl)}

Possible applications of fish collagen hydrolysates are influenced by their solubility and by the effect of $\mathrm{pH}$ on protein solubility determined by its isoelectric point $(\mathrm{pl})$ value. Isoelectric point $(\mathrm{pl})$ is the $\mathrm{pH}$ of the collagen molecule at zero charge. Zeta potential measurements for each fish collagen hydrolysate sample 
at variable $\mathrm{pH}$ were performed (Fig. 4) allowing determination of the isoelectric point considered as the $\mathrm{pH}$ value at which PZ intersects the $x$ axis (equals zero). The calculated values for pl vary between 3.9 and 2.9 as follows: $\mathrm{pl}=2.9$ for sample HO4P1, pl=2.9 for sample HO4P2; $\mathrm{pl}=3.7$ for sample HO4P3 and pl=3.9 for sample H04P4, respectively. Similar values of pl for acid and pepsin-soluble collagen were reported in the literature on the extraction of collagen from fish skin and bones. The pl value differences of collagen hydrolysates samples may be attributed to the ratio of acidic and basic amino acid residues, which was more likely governed by the removal of telopeptides after acidic treatment. Hydrolyzed collagen is an amphoteric macromolecule [28] composed of both acidic $(\mathrm{COOH})$ and basic $\left(\mathrm{NH}_{2}\right)$ functional groups and the $\mathrm{pl}$ decrement could be due to the deamination process. When hydrolyzed collagen was treated at high temperature, the asparagine groups transformed to aspartic acid and the glutamine groups into glutamic acid. This leads to a loss of amino groups and a large relative increase in the carboxyl groups, or a higher content of acidic amino acids, which become dominant, shifting the pl to lower values.

\subsection{Scanning electron microscopy}

Morphology of the obtained fish collagen hydrolysates was investigated using Optical microscopy and Scanning electron microscopy. The optical microscopy results (Fig. S2 supplementary information) confirm the presence of fibrils structure of collagen similar to other reported by literature data [29]. More detailed visual insights were obtained from SEM micrographs (Fig. 5), for all collagen hydrolysate samples a characteristic highly entangled structure, like sheets folded and wrinkled was identified. Both SEM and optical microscopy observations revealed a randomly distributed fibril pattern and confirmed the absence of undesired aggregates (cell debris, skeletal parts or undissociated collagen fibers) between the fibrils of collagen [30].

\subsection{Biocompatibility assessment}

Human adult keratinocytes, HaCaT cell line proliferation experiments cultured for 6 days on medium supplemented with $1 \%$ fish collagen hydrolysates and investigated using phase contrast microscopy (Fig. 6a) revealed no obvious differences in cell morphological aspect for the fish collagen hydrolysates and control, with the exception of the cells cultured in the presence of sample H04P2 which was not associated with a confluent layer at the end of the incubation period. This result suggests that, at $1 \%$ concentration in culture medium, most of the fish collagen hydrolysates samples sustained cell proliferation.

This first observation was supported by the quantification of cell viability using the XTT assay (Fig. $6 \mathrm{~b}$ ) at the end of the 6 days cultivation period. The percentage of viable cells for the fish collagen hydrolysates was above 80\%, except for the sample H04P2. Furthermore, all 3 samples - H04P1, H04P3 and H04P4, showed a higher viability compared to the control bovine hydrolysate, suggesting a superior effect for biomedical applications. An explanation for low biocompatibility of fish sample hydrolysate H04P2 may be the highest molecular mass of its component polypeptides as compared to other samples (as estimated from amine nitrogen content) assumption sustained by other literature reports. 


\section{Conclusions}

Biocompatible fish collagen hydrolysates were obtained from waste carp skin by neutral hydrolysis, using several pretreatment procedures involving organic acids (lactic, citric acid and a 1:1 mixture of both) for removal of residues (scales, bones, meat or fat), followed by removing of non-collagenous proteins with 1 $\mathrm{M} \mathrm{NaOH}, 1 \mathrm{M} \mathrm{NaCl}$, or $1 \mathrm{M} \mathrm{NaHCO}_{3}$ respectively and subsequent defatting and removal of pigments. The highest extraction yield (35\%) was obtained for the sample H04P1, resulted after pre hydrolysis treatment with the mixture of organic acids and $\mathrm{NaOH}$.

A high degree of purity of fish collagen hydrolysates given by percentage of protein (about $98 \%$ ), undetected ash content and the $\mathrm{pH}$ value in the range $6-7$, show that all hydrolysates samples can be safely used in food supplements or cosmetics. The purity was confirmed by the absence of undesired aggregates in the characteristic fibril structure as determined by optical and scanning electron microscopy.

A random coil structure, specific of the denatured collagen (hydrolyzed collagen) with no triple helical structure characteristics was attributed to all neutral hydrolysis obtained collagen hydrolysate samples by examining FT-IR spectra after deconvolution of characteristic amide I band, conclusion sustained by Circular Dichroism Spectroscopy and X-ray diffraction. Moreover, fibril distribution and orientation determined by XRD analyses revealed similar values of distance between skeletons to those measured for collagen hydrolysates extracted from other fish species.

The biocompatibility assessment revealed that the obtained fish collagen hydrolysates had no cytotoxic effect on Human keratinocytes, except for the sample with the highest molecular mass, H04P2. Furthermore, the cell viability for these samples was $80 \%$, higher than that for the conventional bovine hydrolysate.

In conclusion, carp skin collagen hydrolysates obtained by neutral hydrolysis with proved biocompatibility provides attractive alternative source to bovine collagen, with characteristics suitable for potential application in foods, cosmetics and pharmaceutical industry.

\section{Declarations}

\section{Conflict of interest}

The authors declare no competing financial interest.

\section{Acknowledgements}

The work has been funded by the Operational Programme Human Capital of the Ministry of European Funds through the Financial Agreement 51668/09.07.2019, SMIS code 124705. 


\section{References}

1. Gelsea, K., Poschlb, E., Aigner, T.: Collagens-structure, function, and biosynthesis. Adv. Drug Deliv. Rev 55, 1531 - 1546 (2003).

2. Myllyharju, J., Kivirikko, K.I.: Collagens, modifying enzymes and their mutations in humans, flies and worms. Trends Genet. 20, 33-43 (2004).

3. Hong, H., Fan H, Chalamaiah, M., Wu, J.: Preparation of low-molecular-weight, collagen hydrolysates (peptides): Current progress, challenges, and future perspectives. Food Chem. 301, 125222 (2019).

4. Soderhall, C., Marenholz, I., Kerscher, T., Ruschendorf, F., Esparza-Gordillo, J., Worm, M., Gruber, C., Mayr, G., Albrecht, M., Rohde, K., Schulz, H., Wahn, U., Hubner N., Lee, Y. A.:Variants in a novel epidermal collagen gene (COL29A1) are associated with atopic dermatitis. PLOS Biol. 5 (9), e242 (2007).

5. Schmidt, M.M., Dornelles, R.C.P., Mello, R.O., Kubota, E.H., Mazutti, M.A., Kempka, A.P., Demiate, I.M.: Collagen extraction process. Int. Food Res. J. 23, 913-922 (2016).

6. Aberoumand, A.: Comparative study between different methods of collagen extraction from fish and its properties. World Appl. Sci. J. 16, 316- 319 (2012).

7. Alves, A.L., Marques, A.L.P., Martins, E., Silva, T.H., Reis, R.L.: Cosmetic potential of marine fish skin collagen. Cosmetics. 4, 39 (2017).

8. Silva, T.H., Moreira-Silva, J., Marques, A.L. P., Domingues, A., Bayon, Y., Reis, R. L.: Marine origin collagens and its potential applications. Mar. Drugs. 12, 5881-5901 (2014).

9. Nasri, M.: Bioactive Peptides from Fish Collagen Byproducts: A Review, in Byproducts from Agriculture and Fisheries: Adding Value for Food, Feed, Pharma, and Fuels, ed. by Simpson BK, Aryee ANA and Toldra F, John Wiley \& Sons Ltd., 309-333 (2019).

10. Ishak, N.H., Sarbon, N.M.: A Review of Protein Hydrolysates and Bioactive Peptides Deriving from Wastes Generated by Fish Processing. Food Bioproc Tech. 11, 2 - 16 (2018).

11. Zamorano-Apodaca, J.C., García-Sifuentes, C.O., Carvajal-Millán, E., Vallejo-Galland, B., ScheurenAcevedo, S.M., Lugo-Sánchez, M.E.: Biological and functional properties of peptide fractions obtained from collagen hydrolysate derived from mixed by-products of different fish species. Food Chem. 331, 127350 (2020).

12. Marcet, I., Álvarez, C., Paredes, B., Díaz, M.: The use of sub-critical water hydrolysis for the recovery of peptides and free amino acids from food processing wastes. Review of sources and main parameters. J. Waste Manag. 49, 364-371 (2016).

13. Ahmed, R., Chun, B-S.: Subcritical water hydrolysis for the production of bioactive peptides from tuna skin collagen. J Supercrit Fluids. 141, 88-96 (2018).

14. Carvalho, A.M., Marques, A.P., Silva, T.H., Reis, R.L.: Evaluation of the potential of collagen from codfish skin as a biomaterial for biomedical applications. Mar. Drugs. 16, 495 (2018).

15. Kittiphattanabawon, P., Benjakul, S., Sinthusamran, S., Kishimura, H.:Characteristics of collagen from the skin of clown featherback (Chitala ornata). J. Food Sci. Technol. 50, 1972-1978 (2015). 
16. Duan, R., Zhang, J., Dua, X., Yao, X., Konno, K.: Properties of collagen from skin, scale and bone of carp (Cyprinus carpio). Food Chem. 112, 702-70 (2009).

17. Haibo, W., Yanping, L., Haiyin, W., Hanjun, Z., Min, W., Liangzhong, L.: Physical-Chemical Properties of Collagens from Skin, Scale, and Bone of Grass Carp (Ctenopharyngodon idellus). J. Aquat. Food Prod. Technol. 23, 264-277 (2014).

18. Mahboob, S., Haider, S., Sultana, S., Al-Ghanim, K.A., Al-Misned, F., Al-Kahem Al-Balawi, H.F., Ahmad, Z.: Isolation and characterisation of collagen from the waste material of two important freshwater fish species. J. anim. plant sci. 24 (6), 1802-1810 (2014).

19. Morais, H.A., Silvestre, M.P.C., Silva, V.D.M., Silva, M.R., Simoes e Silva, A.C., Silveira, J.N.: Correlation between the degree of hydrolysis and the peptide profile of whey protein concentrate hydrolysates: effect of the enzyme type and reaction time. Am. J. Food Technol. 8, 1-16 (2013).

20. Trandafir, V., Popescu, G., Albu, M.G.., lovu, H., Georgescu, M.: Bio- products based on collagen ("Bioproduse pe bazã de colagen"). Ars Docendi Publishing House, Bucharest, 119-147 (2007).

21. Niculescu, M., Bajenaru, S., Gaidau, C., Simion, D., Filipescu, L.: Extraction of the Protein Components as Amino-Acids Hydrolysates from Chrome Leather Wastes Through Hydrolytic Processes. Rev. Chim. 60, 1070-1078 (2009).

22. León-López, A., Fuentes-Jiménez, L., Hernández-Fuentes, A.D., Campos- Montiel, R.G., Aguirre-Álvarez, G.: Hydrolysed collagen from sheepskins as a source of functional peptides with antioxidant activity. Int. J. Mol. Sci. 20, 3931 (2019).

23. Muyonga, J.H, Cole, C.G.B., Duodu, K.G.: Fourier transform infrared (FTIR) spectroscopic study of acid soluble collagen and gelatin from skins and bones of young and adult Nile perch (Lates niloticus). Food Chem. 86, 325-332 (2004).

24. Rabotyagova, O. S., Cebe, P., David, L.: Collagen structural hierarchy and susceptibility to degradation by ultraviolet radiation. Mater. Sci. Eng. C. 28, 1420-1429 (2008).

25. Kelly, S.M., Price, N.C.: The Use of Circular Dichroism in the Investigation of Protein Structure and Function. Curr. Protein Pept. Sci. 1, 349-384 (2000).

26. Yang, L., Yanwen, L., Zongliang, D., Guoying, L..: Comparison of dynamic denaturation temperature of collagen with its static denaturation temperature and the configuration characteristics in collagen denaturation processes. Thermochim. Acta. 469, 71-76 (2008).

27. Sun, L., Hou, H., Li, B., Zhang, Y.: Characterization of acid- and pepsin- soluble collagen extracted from the skin of Nile tilapia (Oreochromis niloticus). Int. J. Biol. Macromol. 99, 8-14 (2017).

28. Woo, J.W., Yu, S.J., Cho, S.M., Lee, Y.B., Kim, S.B.: Extraction optimization and properties of collagen from yelowfin tuna (Thunnus albacares) dorsal skin. Food Hydrocoll. 22, 879-887 (2008).

29. Hee-Seok, J., Jayachandran, V., Se-Kwon, K., Isolation and characterization of collagen from marine fish (Thunnus obesus). Biotechnol. Bioprocess Eng. 18, 1185-1191(2013).

30. Yaowen, L., Donghui, M., Yihao, W., Wen, Q.: A comparative study of the properties and selfaggregation behavior of collagens from the scales and skin of grass carp (Ctenopharyngodon idella), Int. J. Biol. Macromol. 106, 516-522 (2018). 
31. Berridge, M.V., Herst, P.M., Tan, A.S.:, Tetrazolium dyes as tools in cell biology: New insights into their cellular reduction. . Biotechnol. Annu. Rev. 11, 27-152 (2005).

\section{Tables}

Table 1. The physico-chemical properties of fish skin collagen hydrolysates

\begin{tabular}{|c|c|c|c|c|c|}
\hline \multicolumn{5}{|l|}{ Characteristics } & \multirow[t]{2}{*}{$\begin{array}{l}\text { Method } \\
\text { standard }\end{array}$} \\
\hline & H04P1* & H04P2* & H04P3* & H04P4* & \\
\hline Dried substance, \% & $92.89 \pm 0.39$ & $91.18 \pm 0.38$ & $92.13 \pm 0.38$ & $91.06 \pm 0.38$ & $\begin{array}{l}\text { SR EN ISO } \\
4684: 2006\end{array}$ \\
\hline Ash content, \% & undetectable & undetectable & undetectable & undetectable & $\begin{array}{l}\text { SR EN ISO } \\
4047: 2002\end{array}$ \\
\hline Total nitrogen, \% $\left(\mathrm{N}_{\mathrm{t}}\right)$ & $17.41 \pm 0.11$ & $17.38 \pm 0.11$ & $17.44 \pm 0.11$ & $17.55 \pm 0.12$ & $\begin{array}{l}\text { SR ISO } \\
5397: 1996\end{array}$ \\
\hline Protein substance, \% & $97.84 \pm 2.61$ & $97.68 \pm 2.59$ & $97.99 \pm 2.61$ & $98.62 \pm 2.62$ & $\begin{array}{l}\text { SR ISO } \\
\text { 5397:1996 }\end{array}$ \\
\hline $\mathrm{pH}$ & $6.94 \pm 0.1$ & $6.24 \pm 0.1$ & $6.15 \pm 0.1$ & $6.18 \pm 0.1$ & $\begin{array}{l}\text { SR EN ISO } \\
\text { 4045:2008 }\end{array}$ \\
\hline $\begin{array}{l}\text { Amine nitrogen, \% } \\
\left(\mathrm{NH}_{2}\right)\end{array}$ & 0.71 & 0.55 & - & 3.77 & $\begin{array}{l}\text { ICPI } \\
\text { protocol }\end{array}$ \\
\hline $\mathrm{DH}, \%$ & 4.08 & 3.16 & & 26.49 & \\
\hline
\end{tabular}

Table 2. Location and percent area contribution of FTIR amide I band component peaks for fish skin hydrolysates 


\begin{tabular}{|c|c|c|c|c|c|c|c|c|}
\hline \multirow[t]{2}{*}{ sample } & \multicolumn{8}{|c|}{$\begin{array}{l}\text { Component peak location }\left(\mathrm{cm}^{-1}\right) \text { and percent area, } \% \text { (in brackets) contribution of total } \\
\text { band }\end{array}$} \\
\hline & $1\left[\mathrm{~cm}^{-1}\right]$ & area & $2\left[\mathrm{~cm}^{-1}\right]$ & area & $3\left[\mathrm{~cm}^{-1}\right]$ & area & $4\left[\mathrm{~cm}^{-1}\right]$ & area \\
\hline H04P1 & 1625.88 & $\begin{array}{l}1.243 \\
(29.10)\end{array}$ & 1656.32 & $\begin{array}{l}2.5511 \\
(59.00)\end{array}$ & 1681.87 & $\begin{array}{l}0.0074 \\
(0.22)\end{array}$ & 1691.08 & $\begin{array}{l}0.2331 \\
(5.40)\end{array}$ \\
\hline H04P2 & 1627.21 & $\begin{array}{l}3.3059 \\
(28.50)\end{array}$ & 1651.54 & $\begin{array}{l}6.9176 \\
(59.60)\end{array}$ & 1664.41 & $\begin{array}{l}0.5039 \\
(0.44)\end{array}$ & 1693.67 & $\begin{array}{l}0.4182 \\
(3.60)\end{array}$ \\
\hline H04P3 & 1626.36 & $\begin{array}{l}3.8727 \\
(26.80)\end{array}$ & 1652.03 & $\begin{array}{l}8.5713 \\
(59.40)\end{array}$ & 1674.88 & $\begin{array}{l}1.3539 \\
(9.40)\end{array}$ & 1693.7 & $\begin{array}{l}0.2671 \\
(1.90)\end{array}$ \\
\hline H04P4 & 1628.31 & $\begin{array}{l}3.5362 \\
(28.20)\end{array}$ & 1651.27 & $\begin{array}{l}7.8129 \\
(62.50)\end{array}$ & 1661.25 & $\begin{array}{l}0.7015 \\
(5.60)\end{array}$ & 1694.06 & $\begin{array}{l}0.1671 \\
(1.30)\end{array}$ \\
\hline
\end{tabular}

\section{Figures}


acid Carp skin $\longrightarrow \begin{gathered}\text { washing with } \\ \text { organic detergent }\end{gathered}$

remove meat, scales and fat

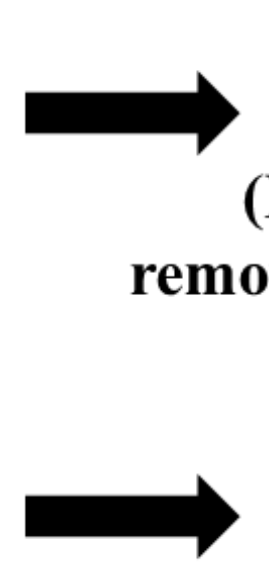

hydrogen peroxide treatment remove pigments

alkaline treatment

$\left(\mathrm{NaHCO}_{3}, \mathrm{NaOH}, \mathrm{NaCl}\right)$

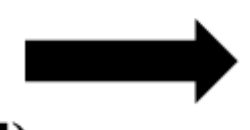

teins

\author{
Ethanol \\ Treatment \\ remove fats
}

treatment
(lactic, citric,
lactic+citric)

treatment
(lactic, citric,
lactic+citric)
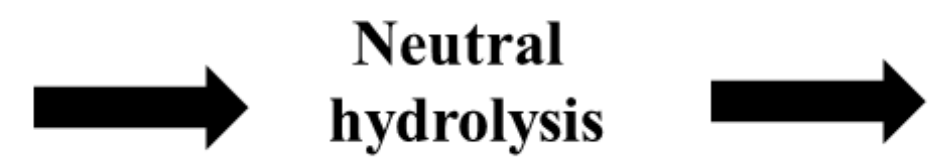

\section{Freeze-drying}

hydrolyzate fish collagen

Figure 1

Extraction process for fish skin collagen hydrolysates 


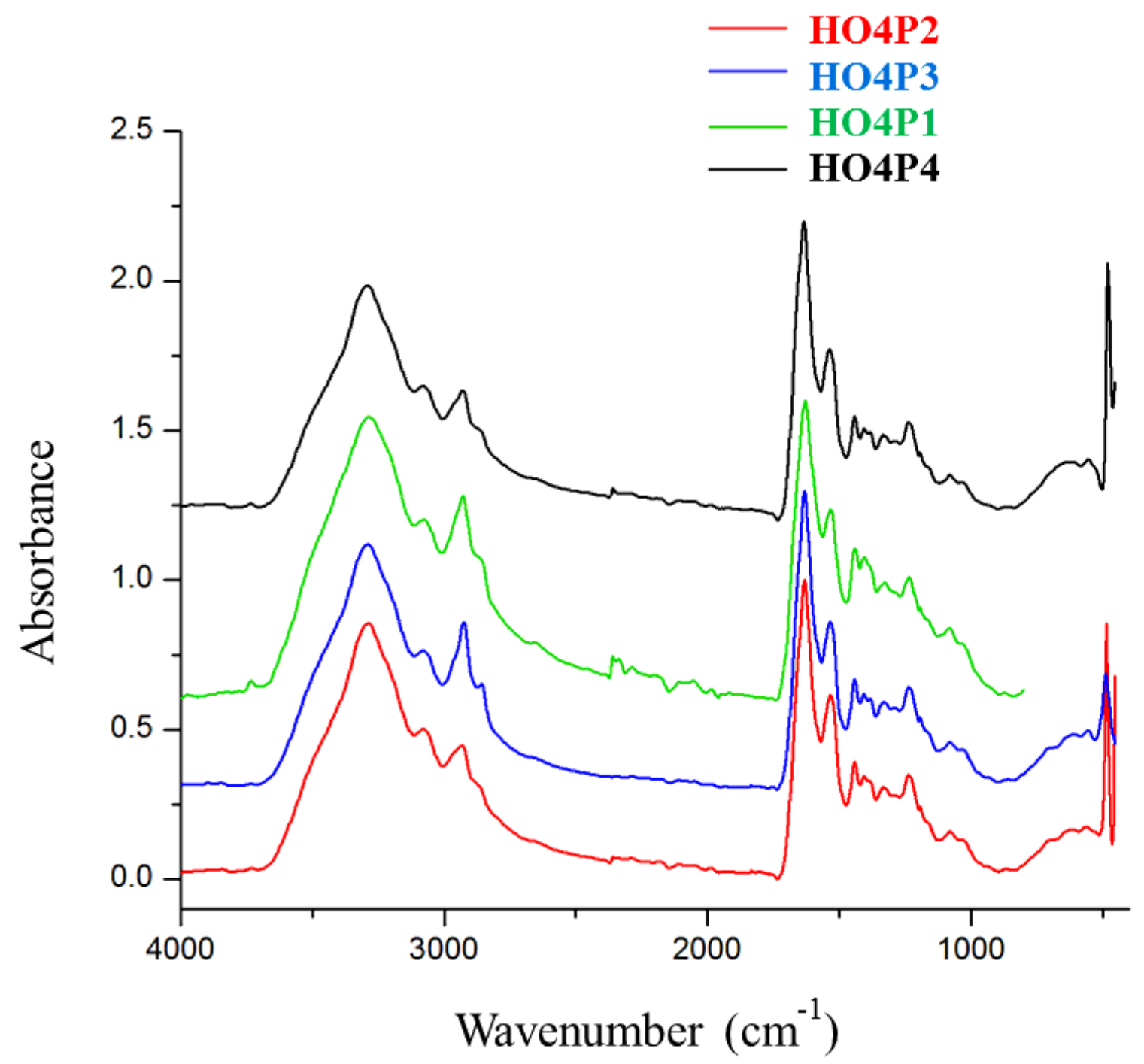

Figure 2

FTIR spectrum for fish collagen hydrolysates; 


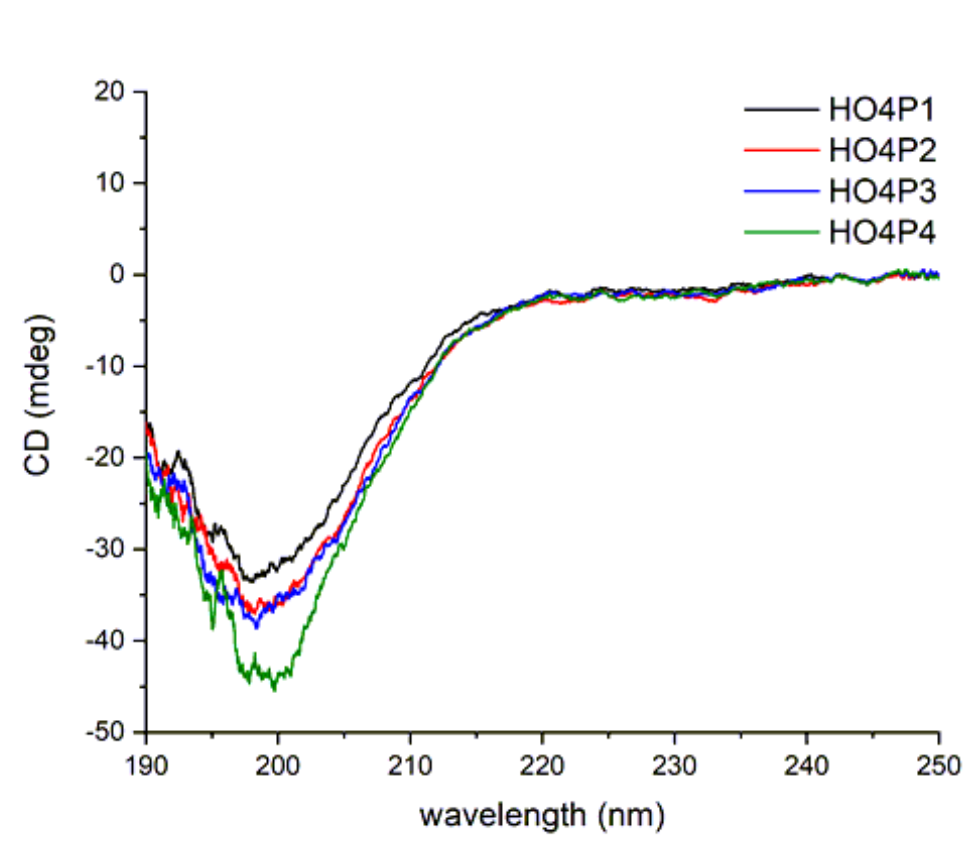

a)

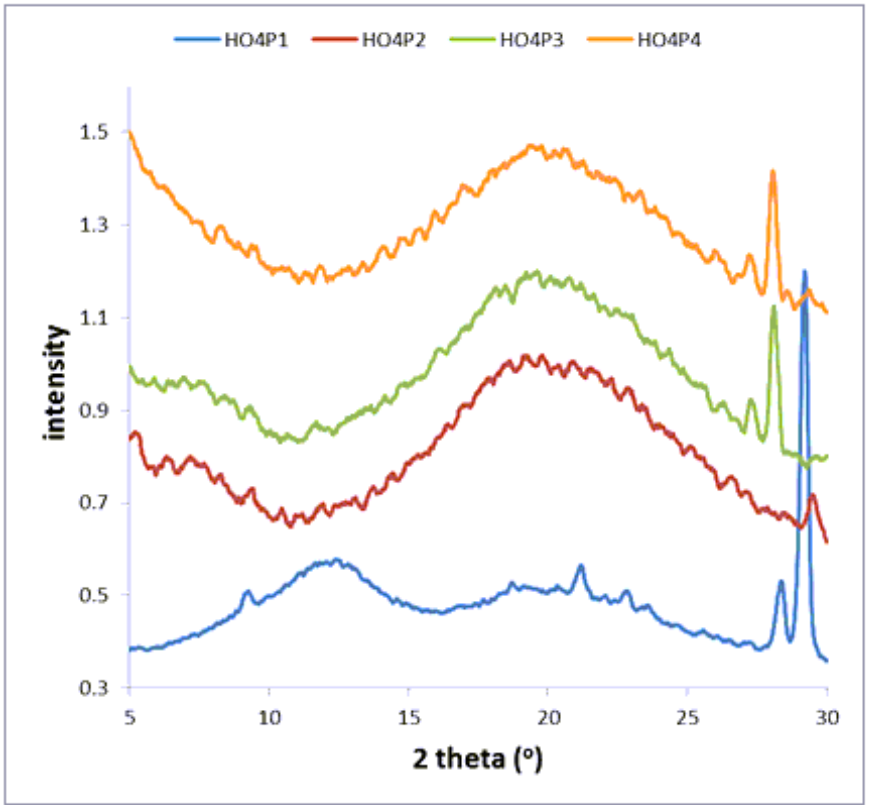

b)

\section{Figure 3}

a) CD spectra of the analyzed fish skin collagen hydrolysates b) X-ray diffraction spectra of fish skin collagen hydrolysates 


\section{Isoelectric point}

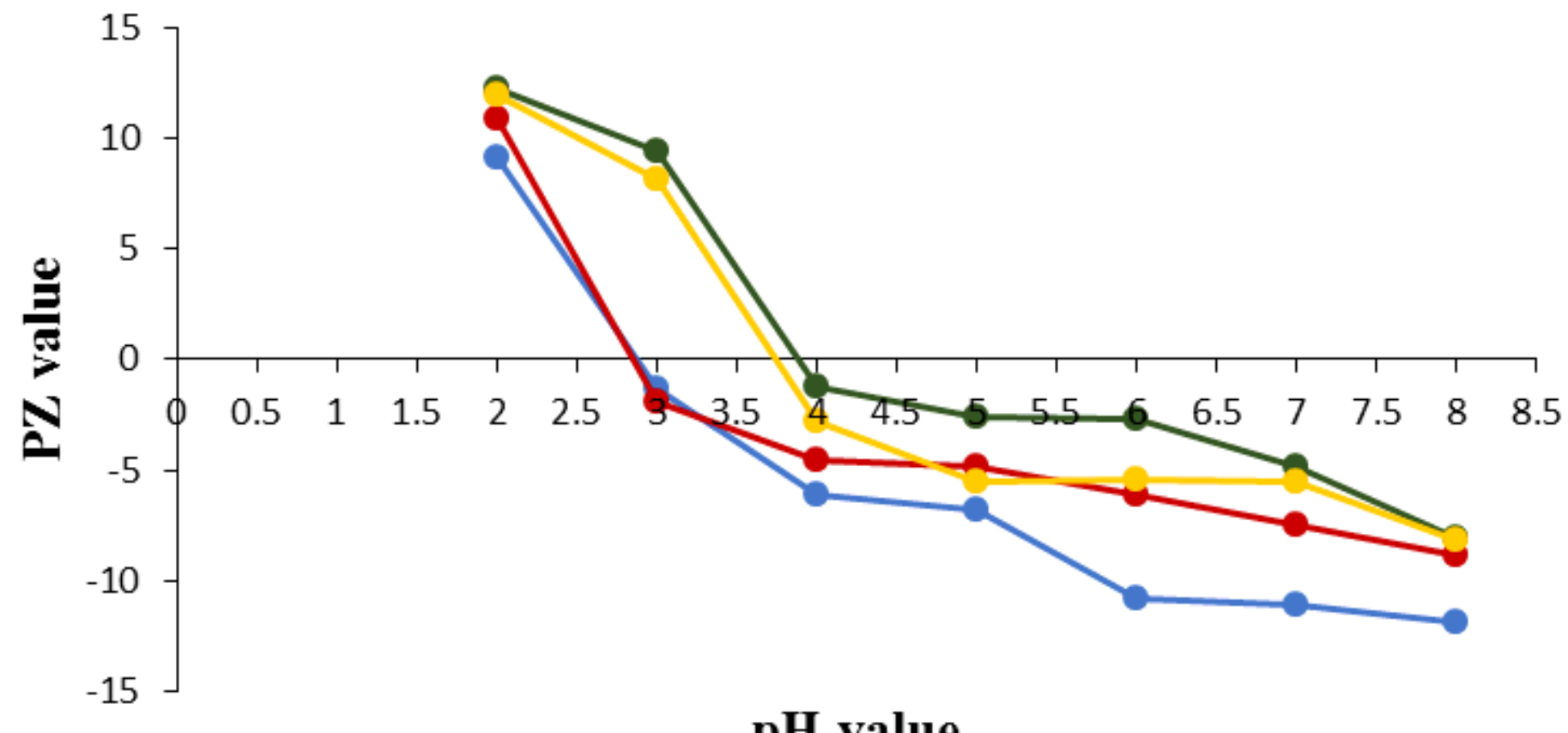

pH value

$\multimap$ HO4P1 $\rightarrow$ HO4P2 $\rightarrow$ HO4P3 $\rightarrow$ HO4P4

Figure 4

Isoelectic point (pl) for fish skin collagen hydrolysates 
a)
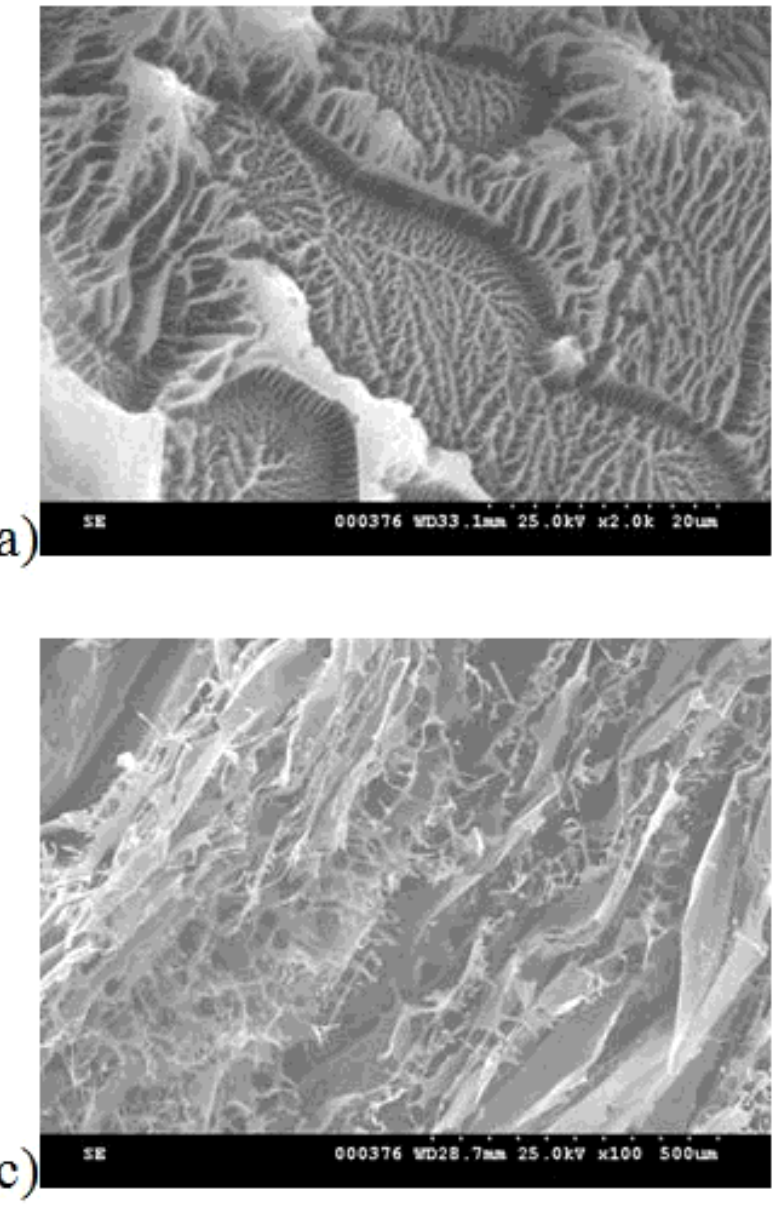
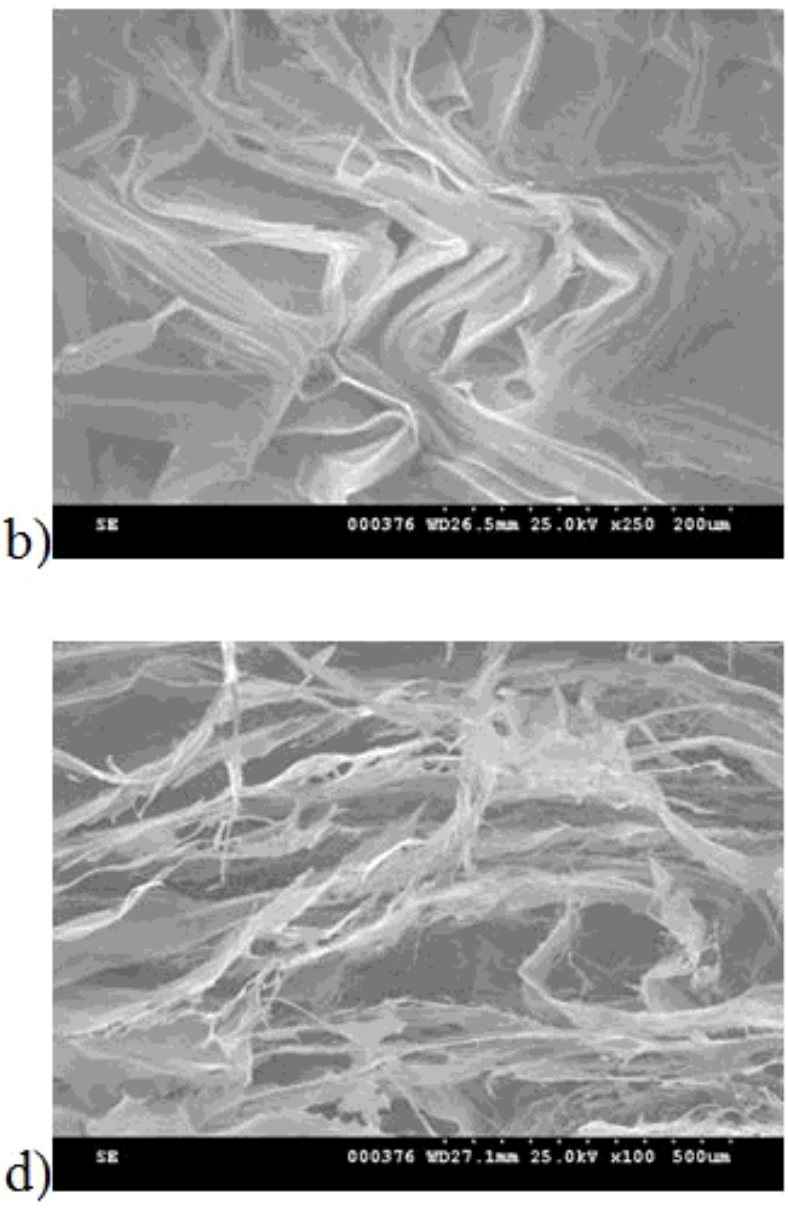

Figure 5

Scanning electron microscopy images for fish skin collagen hydrolysates (a: H04P1, b: H04P2, c: H04P3, d: HO4P4) 

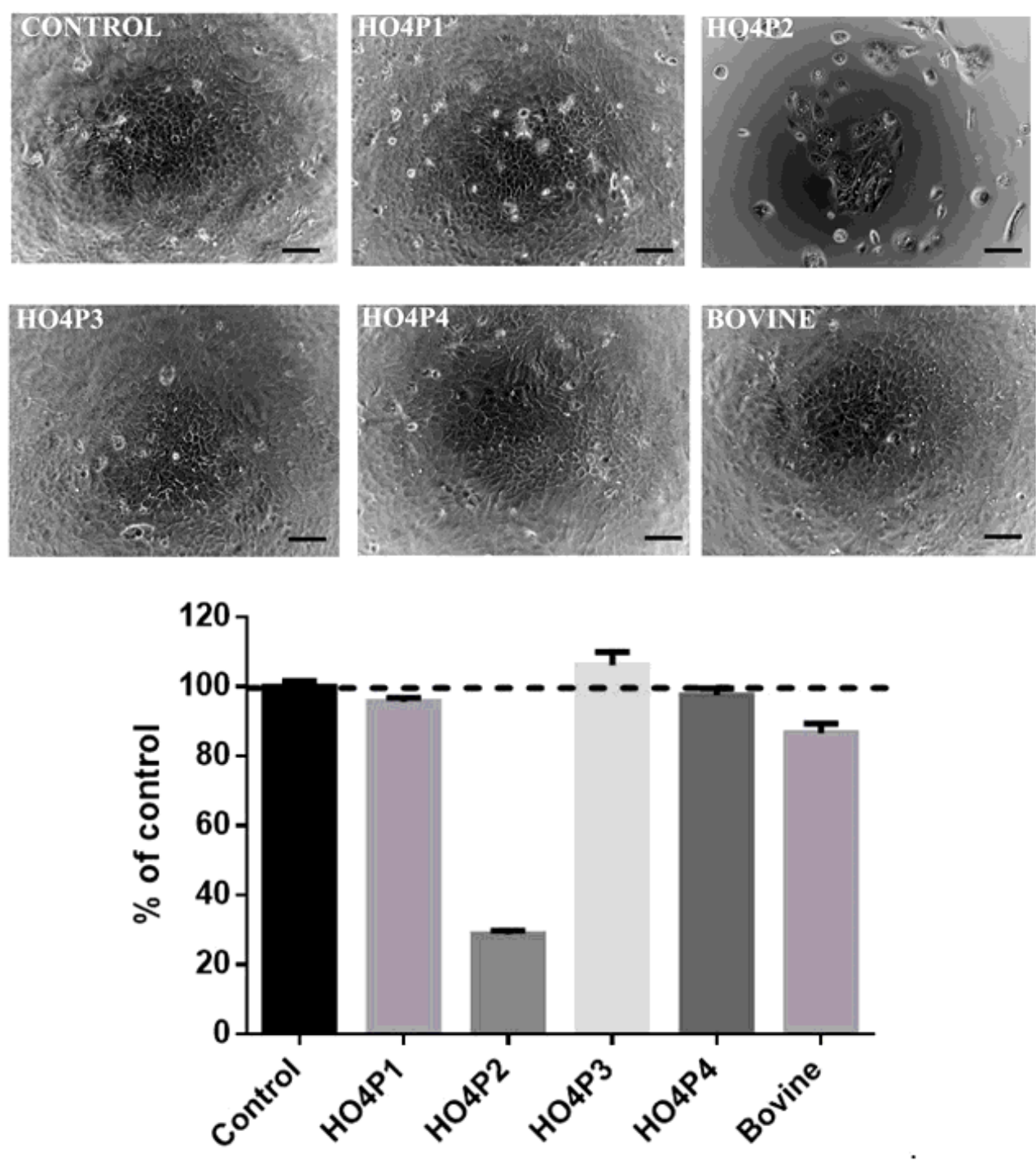

Figure 6

a) Optical microscopy images for keratinocytes cultured in the presence of fish collagen hydrolysates H04P1-H04P4. Scale bare represents $100 \mu \mathrm{m}$. b) Viability of keratinocytes cultured in the presence of fish skin collagen hydrolysates $\mathrm{N}=3$ per group. ${ }^{*} \mathrm{P}<0.05$ compared with the control group, NS- not significant

\section{Supplementary Files}

This is a list of supplementary files associated with this preprint. Click to download.

- Graphicalabstractrev.tif

- Supplementarymaterial.docx 